\title{
Bacterial Community Structure in Waste Water Treatment
}

\author{
Hiral Borasiya \& Shah MP \\ Division of Applied \& Environmental Microbiology, Enviro Technology Limited, \\ Industrial Waste Water Research Laboratory, Gujarat, India \\ shahmp@beil.co.in
}

\begin{abstract}
All data suggest that microbial community structures or samples of sludge with a content of phosphate between 8 and $12 \%$ were very similar but distinct from those containing phosphate at $1.8 \%$. In all samples analyzed, ubiquinones, menaquinone and fatty acids were the main components. Dominance and E5 suggested that a large number of organisms belonging to the $b$ and subclasses Proteobacteria and Actinobacteria from higher GMC Gram-positive bacteria, respectively, were present. Denaturing gradient gel electrophoresis analysis revealed at least 6-10 predominant DNA bands and numerous other fragments in each sample. Five major denaturing gradient gel electrophoresis fragments from each of $1.8 \%$ and $11.8 \%$ phosphate containing sludge samples, respectively, were successfully isolated and sequenced. Phylogenetic analysis of the sequences revealed that both $3 \%$ and $15 \%$ phosphate -containing sludge samples shared three common phylotypes which are separately associated with new bacterial groups of subclass C Proteobacteria, two E5 containing Actinobacteria, and Caulobacter spp. The subclass Proteobacteria. Phylogenetic analysis revealed useful phylotypes unique for both samples sludge. Therefore, changes in the phosphate content did not affect the composition and quantity prevailing microbial population, although specific phylotypes could not be unambiguously associated with EBPR.
\end{abstract}

Keywords: Activated sludge; Biomarker; DGGE; $16 \mathrm{~S}$ rDNA; Caulobacter.

\section{INTRODUCTION}

Nowadays, biological wastewater treatment plants are the most common biotechnological application in the world (Seviour, 2010). More than 15,000 WWTPs operate in the United States alone, $75 \%$ of which include a secondary biological treatment, processing billions of liters of sewage per day (Bitton $\mathrm{G}, 2011$ ). From the various alternatives of biological treatment systems that exist, conventional activated sludge (CAS) bioreactors are by far the most commonly used secondary treatment technology (Graham DW, 2004). Despite of periodic improvements to the technology since its invention almost a century ago (Graham DW, 2004) and its ubiquitous global application, little is known about the underlying factors controlling the complex dynamics of the microbial populations interacting in the bioreactors and how those dynamic interactions affect the system's functional stability (Wang X, 2011). Methods based on the analysis of various biomarkers and 16S rRNA genes (rDNA) have been used to characterize and monitor microbial communities in various ecological systems. The biomarkers, cellular fatty acids and respiratory quinones, have been used routinely in taxonomy to characterize, differentiate and identify genera, species, and strains of bacteria (Staley et $a l, 1989)$. Some studies have further shown that the biomarker 'signature' of environmental samples can be statistically analysed and applied to differentiate community profiles (Haack et al, 1994; Hiraishi et al, 1989, 1998). 16S rDNA-based methods can provide more information on the phylogenetic structure of microbial communities than the biomarker method (Bond et al, 1995; Muyzer et al, 1993). The number and intensity of resolved fragments gives an approximate estimate of the diversity of the predominant species, and further purification of fragments and sequence analysis provides an insight into the phylogenetic affiliation of individual populations (Muyzer et al, 1995; Nielsen et al, 1999). Combining the biomarkers and 16S rDNA-based approaches should greatly enhance the characterization of microbial communities found in various systems. At a $11.8 \%$ phosphate content the community was predominated by rod-shaped organisms that accumulated both polyphosphate and PHA, whereas at a $1.8 \%$ P content the community was dominated by PHAaccumulating cocci that neither accumulated polyphosphate nor aerobically took up phosphate when provided (Liu et al, 1996, 1997a). It was suspected that the loss of polyphosphate accumulating 
bacteria upon shifting the feed composition was due to loss of their energy pool (polyphosphate) which they used to transport and store carbon (e.g. PHA) under anaerobic conditions so that it could be subsequently used for growth under aerobic conditions. Our initial assumption was that polyphosphate accumulating bacteria would constitute a predominant fraction of the bacterial population in a $11.8 \%$ phosphate-containing sludge, and on altering sludge phosphate content to $1.8 \%$, could be easily differentiated from non-polyphosphate accumulating bacteria using the biomarker and denaturing gradient gel electrophoresis approaches. Furthermore, the phylogenetic affiliation of the predominant populations in $1.8 \%$ and $11.8 \%$-phosphate containing sludge could be easily identifiable from sequence analysis of the predominant $16 \mathrm{~S}$ rDNA denaturing gradient gel electrophoresis fragments. This study was aimed at testing the above assumption.

\section{METHODS}

\subsection{Activated Sludge Enrichment}

Three sequential batch reactors (A1, A2 and A3) were used with a mixture of acetate and peptone as carbon sources in alternating anaerobic and aerobic conditions as previously described (Liu et al 1994, 1997). All reactors were subjected to eight rounds of 3 hours per day, which consisted of a $50 \mathrm{~min}$ period followed by anaerobic aerobic phase of $80 \mathrm{~min}$ and $50 \mathrm{~min}$ and the sediment phase. Early in the anaerobic phase, the substrate was introduced to maintain an organic load of $0.38-0.88 \mathrm{~kg} / \mathrm{cm}^{2}$, third residence time of the sludge was maintained between 7 and $8 \mathrm{~d}$, and $\mathrm{pH}$ was controlled between 7 and 8 . The phosphate content in each loop reactor was controlled between about 1.8 and $14 \%$ using total organic carbon reports from different phosphate (Liu et al, 1997a).

\subsection{Chemotaxonomic Biomarker Analyses}

Procedures for the analysis of respiratory tract-quinone were described by Hiraishi et al. (1989). In short, respiratory quinones were extracted with a chloroform: methanol mixture, which was purified by thin layer chromatography and qualitatively analyzed by reverse phase HPLC equipped with an array detector photodiodes. Determination of other quinones, including demethyl menaquinone and rhodoquinone, has not been attempted because these quinones are previously found in the methods of enhanced biological phosphate removal (Hiraishi et al, 1989). Ubiquinones and menaquinones $n$ isoprene units are abbreviated n-Q and E-n, respectively. E-n (Hx) represents a partially hydrogenated menaquinone $\mathrm{x}$ with hydrogen atoms on the side chain containing $\mathrm{n}$ isoprene units. Total cellular fatty acids were analyzed using a protocol described by Rajendran et al. (1992). Cluster analysis (statistical) was used to statistically distinguish models in the respiratory quinone and total cellular fatty acid data. Dendrograms were constructed using the unique link and euclidean distance rules in the statistical program. The analysis of variance was also used to test the changes in individual quinone components from mud samples from the reactors containing different phosphate contents sludge.

\subsection{PCR Amplification and Isolation of DNA}

Deoxyribo nucleic acid from activated sludge was obtained after cell lysis, extraction with chloroform, phenol and precipitation with ethanol using a protocol described previously (Liu et al, 1997b). This DNA preparation was used as a template in PCR mixtures-a reaction which contained 1x PCR buffer, 200 microM each dNTP, $1.5 \mathrm{mM} \mathrm{MgCl}_{2}, 0.1$ microM each loop primer, $5 \%$ DMSO and $2.5 \mathrm{U}$ Taq DNA polymerase in a final volume of $100 \mathrm{ml}$. For the amplification of 16S rDNA for denaturing gradient gel electrophoresis analysis, 968FGC forward primer with a GC-clamp (Heuer et al, 1997) and reverse primer 1392R (Ferris et al, 1996) were used. The polymerase chain rection was performed in a Perkin Elmer 9600 thermocycler using a thermal program described previously (Nielsen et al, 1999). Amplification of DNA was verified by electrophoresis of $2 \mathrm{ml}$ of the PCR product on a $1 \%$ gel agarose in TAE $1 \mathrm{X}$ buffer $(20 \mathrm{mM}$ Tris-acetate, $\mathrm{pH} 7.4,10 \mathrm{mM}$ sodium acetate, $0.5 \mathrm{mM}$ EDTA).

\subsection{Denaturing Gradient Gel Electrophoresis}

Denaturing Gradient Gel Electrophoresis was carried out using a D-Gene system according to manufacturer's instructions. PCR products were loaded onto an acrylamide gel at $6 \%$ in $1 \mathrm{X}$ TAE buffer. The denaturing gradient in the gel was formed by mixing two stock solutions of $6 \%$ acrylamide containing $40 \%$ denaturing formamide and $60 \%$ denaturing formamide deionized with a denaturing AG501-X8 mixed bed resin before being used. DNA fragments were visualized by silver staining as described by Riesner et al. (1989). 


\subsection{Isolation, Cloning and Sequencing}

Deoxyribo nucleic acid sequences of specific fragments in the denaturing gradient gel electrophoresis gels were determined. Fragment was excised from the gel with a razor blade and the DNA was eluted overnight in 100.1 of buffer of TAE. Each DNA fragments amplified by PCR were DGGE primers described above, ligated into the pCRII vector and transformed into competent $E$. coli cells. Clones having fragments of target DNA were chosen randomly gain acceptance ten clones using the denaturing gradient gel electrophoresis gel primers and comparing the electrophoretic mobility of the amplicon with the fragments in the original sample. The selected DNA fragments were sequenced using 968FGC and terminal 1392R primers and Taq DyeDeoxy Terminator Cycle Sequencing Kit.

\subsection{Phylogenetic Analyses}

Partial DNA sequences obtained in this study were compared with 16S rRNA sequences available in Gen Bank using the NCBI BLAST program. The bridge closely related NCBI blast search sequences and 16S rRNA important sequences of environmental clones and bacterial isolates obtained from EBPR process were retrieved and aligned with these denaturing gradient gel electrophoresis bands sequenced using the Clustal W program (Thompson et al, 1994). A phylogenetic tree was constructed from the evolutionary distance matrix based on the algorithm of two parameters using the method of Kimura neighbor-joining (Saito and Nei, 1987). The analysis was performed with the mega program (Kumar et al, 1993), and the deviation in alignment sites were excluded from the pair wise comparison.

\section{RESULTS AND DISCUSSION}

\subsection{Community Composition as Revealed Using Chemotaxonomic Biomarkers}

Table 1 shows the respiratory quinone profiles of activated sludge samples with different phosphate contents. Both ubiquinone and menaquinones were detected in all sludge samples. S8 and S10 were the most dominant ubiquinones present in all samples, Followed by S7 and S9. The high content of S8 and S10 could reflect the predominance of members of the b and has Subclasses, respectivement, of the Proteobacteria (Hiraishi et al, 1998). E5 was the dominant menaquinone detected (70\%), and is found in mainly members of the Actinobacteria of the high G+C Gram-positive bacteria (Hiraishi et al, 1998). Fatty-acid profiles revealed that two major monounsaturated fatty acids, C16: 1 and C18 and a saturated fatty acid, C16: 0, accounted for more than $60 \%$ of total fatty acids present in all sludge communities. In addition, lower water equivalent of C16: 0i were detected. The profiles of both respiratory quinones and fatty acids for different samples taken from reactors at different phosphate analyzed statistically. Similar results of ANOVA have shown that the difference in the mean percentage of Q8, S10 and E5 was observed between a mud phosphate 1.8\% from R1 and phosphate sludge from the reactor R3 11.8\%. Since Q-8, S10 and E5 (H\%) were the main components of ubiquinone and menaquinone, the difference observed on changing the sludge content phosphate 12.3 to $1.8 \%$ suggested trips population occurring in the chamber of a Proteobacteria subclass and actinobacteria respectively. However, significant differences in -8 Q, Q-10 and E in R1 with $1.8 \%$ phosphate, and R3 with $1.8 \%$ phosphate, it is difficult to draw generalized conclusions about their role in eliminating phosphates. As a result of respiratory quinone profiling, fatty acid data (Figure 1a and 1b) also revealed marked differences in the structure of microbial communities in reactor enhanced biological phosphate removal containing different levels of phosphate.

Table 1. Respiratory quinone profile.

\begin{tabular}{|l|l|l|l|l|l|}
\hline Phosphate content & A1 & A2 & A3 & \multicolumn{1}{l|}{$\mid$} \\
\hline Phosphate/carbon ratio & $1.8 / 0.1527778$ & $7.2 / 0.486111111$ & $1.8 / 2: 100$ & $7.4 / 10: 100$ & $11.8 / 20: 100$ \\
\hline Ubiquinones & & & & & \\
\hline S7 & 0.12 & 1.8 & 0 & 1.74 & 0.58 \\
\hline S8 & 4.8 & 6.8 & 1.2 & 1.28 & 1.28 \\
\hline S9 & 0.28 & 0.48 & 1.4 & 0.74 & 0.74 \\
\hline S10 & 4.9 & 0.92 & 6.5 & 0.91 & 1.3 \\
\hline Menaquinones & & & & & \\
\hline E6 & 0 & 1.5 & 0.5 & 0 & 1.21 \\
\hline E7 & 0 & 0 & 1.28 & 0 & 1.81 \\
\hline E8 & 1.3 & 1.2 & 0.6 & 0.25 & 0 \\
\hline E8 (H4) & 1.7 & 2.8 & 1.4 & 1.4 & 0.91 \\
\hline E9 & 0.8 & 3 & 0.52 & 1.12 & 1.31 \\
\hline E9 (H4) & 0.28 & 1.4 & 1.2 & 0.81 & 0.74 \\
\hline
\end{tabular}




\subsection{Community Structure as Revealed Using DGGE}

The fragments of 16S rDNA genes amplified from sludge samples containing 11.8 (A3), 7.8 (A2 and A3), $1.8 \%$ (A3) phosphate content were solved using denaturing gradient gel electrophoresis (Figure 2). On the basis of the intensity of the fragment of about 8.2 predominant fragments and many others have been observed in each sample. The electrophoretic mobility and intensity of major bands were similar in the sludge samples A3 with phosphate content ranging from 7.8 to $11.8 \%$, suggesting the predominant proposal populations of microbial communities are not detectable different. Furthermore, the grounds of $16 \mathrm{~S}$ rDNA fragments from sludge samples having a phosphate content of about $8 \%$ were very similar to each other, indicating that the enrichment of microbial populations was reproducible to phosphate content. A further reduction of the phosphate content of the sludge from $7.8 \%$ to 2 Detectable caused a change in fingerprints of denaturing gradient gel electrophoresis: at least three of the seven bands dominate the phosphate sludge $8 \%$ have disappeared and six new groups appeared predominant in the phosphate sludge of $1.8 \%$. Obviously, the energy depletion of the pool for carbon uptake excluded some of the dominant microbial populations that were perhaps involved in an enhanced biological phosphate removal activity, leading to the selection of other populations microbial in the process. Consequently, as the results of the biomarker, it can be concluded that the variation of ratio phosphate of 20: 100-2 100 causes not only the decrease in sludge phosphate content, but also the change in the types and plenty of predominantly microbial populations in enhanced biological phosphate removal systems. Referring to: the observation of denaturing gradient gel electrophoresis bands predominant common in both high and low phosphate samples sludge percentage further suggested that the microbial ecology occurring in the system of enhanced biological phosphate removal was more complicated than our initial assumption. This polyphosphate accumulation and non-polyphosphate accumulating bacteria were represented by bands of denaturing gradient gel electrophoresis. Identification of $16 \mathrm{~S}$ rRNA sequences predominant DGGE bands allow such explanations postulated. However, we must recognize that rRNA sequence information rarely allows a physiological function to be assigned to each population. More features, polyphosphate and PHA training are not phylogenetically conserved (Dawes and Senior, 1973).

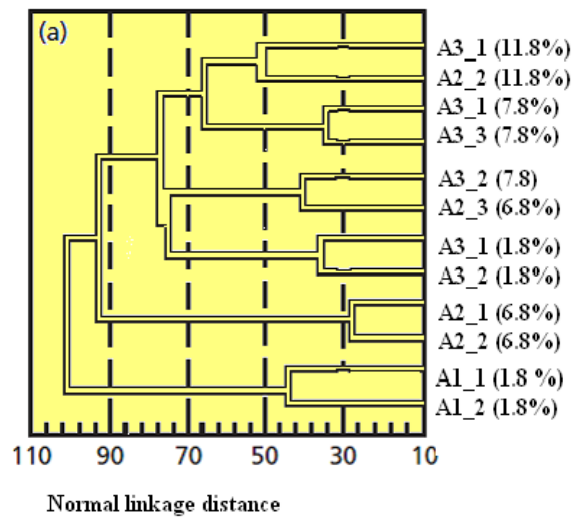

Figure 1a. Dendrogram of the cluster analysis on the profiles of respiratory quinones, And cellular fatty acids.

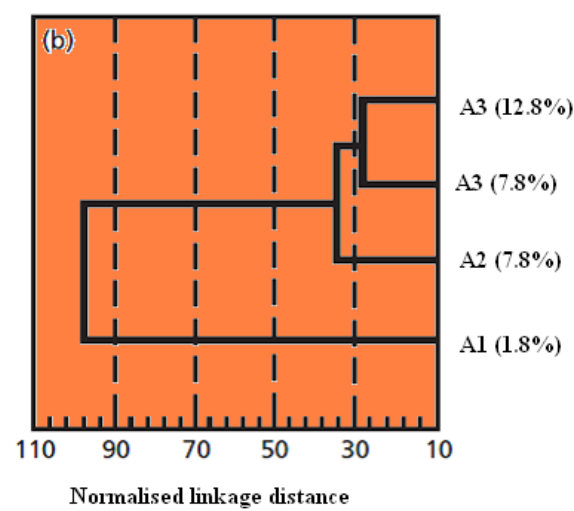

Figure 1b. Dendrogram of the cluster analysis on the profiles of respiratory quinones, For samples containing different sludge P contains. 


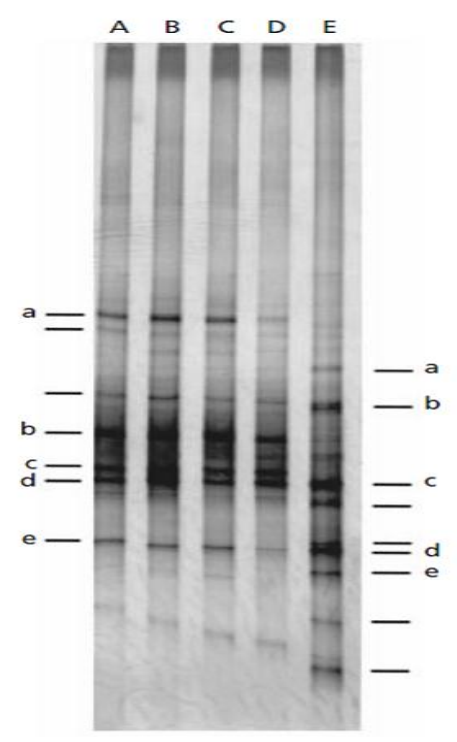

Figure 2. Polymerase chain reaction-Denaturing gradient gel electrophoresis analysis of activated sludge sample.

\subsection{Phylogeny of Predominant Populations}

Seven and nine major fragments from mud samples containing 11.8 and $1.8 \%$ phosphate content, respectively, were excised from the gel and purified. The purified DNA was amplified using the same primers and subjected to denaturing gradient gel electrophoresis in a gel together with the initial sample. Perhaps due to the quality of the recovered DNA, only five large fragments of each sample gave PCR products. Since re-amplification of one fragment often results in the formation of several amplicons, direct sequencing of the fragment could not be re-amplified (data not shown). Instead, the fragment was reamplified cloned and clones with the correct insert were identified by comparing the electrophoretic mobility of the cloned fragments with that of the target fragment found in the original sample. The comparative analysis of these partial 16S rRNA sequences (Figure 3) revealed the phylogenetic affiliation of ten sequences recovered. Among the ten sequences determined, two fragments DGGE found in sludge samples phosphate $1.8 \%$ and $11.8 \%$ were identified. The six remaining fragments were unique and have found that in either $1.8 \%$ or $11.8 \%$ sample phosphate sludge. A pair of common fragments (Figure 2) was closely related to a novel isolated but-not-yetgroup bacterial c subclass of the Proteobacteria (Figure 3) found in anaerobic acetate medium fed by the aerobic activated sludge who has not accumulated phosphate (Nielsen and al, 1999). This group of new bacteria could accumulate granular inclusions, and possibly PHA composed of two populations with identical morphology coccoid (3-4 cells were $~ \operatorname{lm}$ diameter). Large cocci with morphological characteristics similar to those of the group according to the invention have also been observed as a predominant population at the beginning of our $1.8 \%$ phosphate mud sample (Liu et al, 1996). Though the ability of this novel group to accumulate phosphate remains unclear, it was also observed in a good EBPR process with PHA ccumulation. Although the ability of this novel group of accumulating phosphate remains uncertain, it was also observed in a good process EBPR with PHA accumulation by the combination of fluorescent in situ hybridization staining and PHB in (data not presented). This is probably because the group can perform the new carbon metabolism in the process of EBPR, and has not completely overwhelmed by the phosphate batteries. Thus, a low content S9, a major component of the ubiquinone c subclass Proteobacteria (Hiraishi et al, 1998), was observed in all samples of sludge (Table 1). Another common DGGE fragment at both 2 and $12 \pm 3 \%$ Sludge phosphate (Figure 2) was closely linked to the actinobacteria. The cultured bacteria were most closely related two isolates, the strain and $\mathrm{b}$, from the reactor containing 1.8\% phosphate (Liu, 1995). These two isolates accumulated PHA but not polyphosphate granular inclusions and contain the same major menaquinone component [E5 (\% M)] (Liu, 1995) as seen in the sludge sample. It is likely that these two organizations are not particularly involved in phosphorus removal. A good example is between a phosphate-accumulating bacteria, Microlunatus phosphovorus (Nakamura et al, 1995) and nonphosphate accumulating bacteria Micropruina glycogenica (Shintani et al, 2000), two phylogenetically related genera isolated from EBPR process. Since different actinobacteria may contain different proportions of nemaquinones (Collins and Jones, 1981), the observed change in E5 
$(\mathrm{H} \%)$ contained about changing the phosphate content may reflect a population shift between phosphate accumulation and actinobacteria phosphate accumulating with different contents nemaquinone. Nevertheless, these data confirmed that the members of this novel bacterial population of actinobacteria are widely distributed in the EBPR systems, and other reports have suggested (Bond et al, 1999; Hiraishi et al, 1989; Nakamura et al, 1995; Wagner et al, 1994) are partly responsible atoms and optionally phosphate metabolism observed in both reactors $1.8 \%$ and $11.8 \%$ containing phosphate. DGGE fragments (Figure 2) that were phylogenetically related to Caulobacter species of Proteobacteria of the subclass were observed in both the $1.8 \%$ systems and containing $11.8 \%$ phosphate -even though these fragments do not migrate to the same position on the gel, DGGE. It therefore appears, as demonstrated herein and by other studies (Felske and al, 1998;. Nielsen et al, 1999), that of 16S rDNA fragments that are phylogenetically closely related may have different positions migration in a DGGE gel. Caulobacter spp. are often found in environments with low organic carbon content (Stahl et al, 1992), but were detected in sewage treatment systems (MacRae and Smit, 1991) and a process of EBPR full scale (schuppler and al, 1995). The presence of Caulobacter may be a reason for the significant amount S10 detected in all samples of sludge (Table 1). In more common groups, the phylogenetic analysis (Figure 3) revealed fragments or specific bacterial populations in both $1.8 \%$ and $11.8 \%$ of sludge containing phosphate. Due to the sequence of 16S rRNA obtained short and the absence of closely related sequences based on 16S rRNA phylogenetic exact location of these populations was difficult. Band $\mathrm{E}$ (1.8\% phosphate) and the web (11.8\% phosphate) were both associated with the subclass of Proteobacteria. Band v (11.8\% phosphate) and the band b (1.8\% phosphate) were associated with high GC group green sulfur bacteria unidentified, respectively. These results were consistent with the result that significant amounts of S10 and E5 were present in all sludge samples, and a change in their composition about changing the phosphate content was detected. Although these unique populations in the sludge $11.8 \%$ phosphate were perhaps the predominant populations performing metabolism EBPR, capacities regarding the polyphosphate metabolism and PHA is unknown and warrants further study. Furthermore, contrary to the respiratory quinone result, none of the dominant DGGE fragments extracted and sequenced have been associated with the subclass of $\beta$-Proteobacteria. This could be due to our inability to retrieve some sequences of DGGE bands predominant (Figure 2) that may have belonged to the subclass. The stigma associated with the mining community of DNA and PCR amplification in some cases (Picard et al, 1992; Tebbe and Vahjen, 1993; Wilson, 1997) could also lead to misrepresentation of the true fingerprint of the community. It is also possible that the bacteria which produce large amounts of S8, but are not part Proteobacteria b- exist and may be present in the activated sludge systems. In summary, our current understanding of the diversity of microbial populations in the process of EBPR has mainly come from studies using fluorescent in situ hybridization (Bond et al, 1999;. Kammpfer et al, 1996;. Schuppler et al, 1998; Wagner et al, 1994) and analysis of environmental 16S rDNA clone libraries (Bond et al, 1995,. schuppler et al, 1995)... All studies suggest a high degree of phylogenetic diversity, at least 30 different phylotypes Big branches domain bacteria. However, no study to date has identified a specific phylotype directly associated with the polyphosphate accumulation, PHA or both. We first suspected that inconclusive results were attributed to the use of sludge samples from EBPR full scale processes in which the diversity of the population is influenced by a variety of environmental factors (eg, several substrates, electron acceptors and constant changes in the P\} C power ratio) (Cech and Hartman, 1993 ;. Kuba et al, 1993; Liu et al, 1997a), and accumulation of bacteria phosphate are not necessarily the majority population. Our study showed that even in well-controlled EBPR systems and enriched detectable microbial populations were phylogenetically diverse. Although a change in the structure of the microbial community on changing the $\mathrm{P}$ sludge content was observed from the biomarker and fingerprinting DGGE, our results further found that microbial communities in $1.8 \%$ and $11.8 \% \mathrm{P}$ containing mud not only included the predominant bacterial populations specific to each mud, but also populations phylogenetically closely related shared. It was also suspected that the specific phylogenetic groups could include both non-phosphate accumulation and accumulation phosphate populations. Thus, the combined use of biomarkers and methods DGGE was insufficient to identify organisms that accumulate phosphates. One promising approach is to combine micro autoradiography with fluorescent in situ hybridization to link functional traits in phylogenetic population in activated sludge process (Lee et al, 1999). This approach with refined hierarchical set of probes (eg Mobarry et al, 1996; Raskin et al, 1994) should allow a better understanding of the organizations responsible for EBPR. 


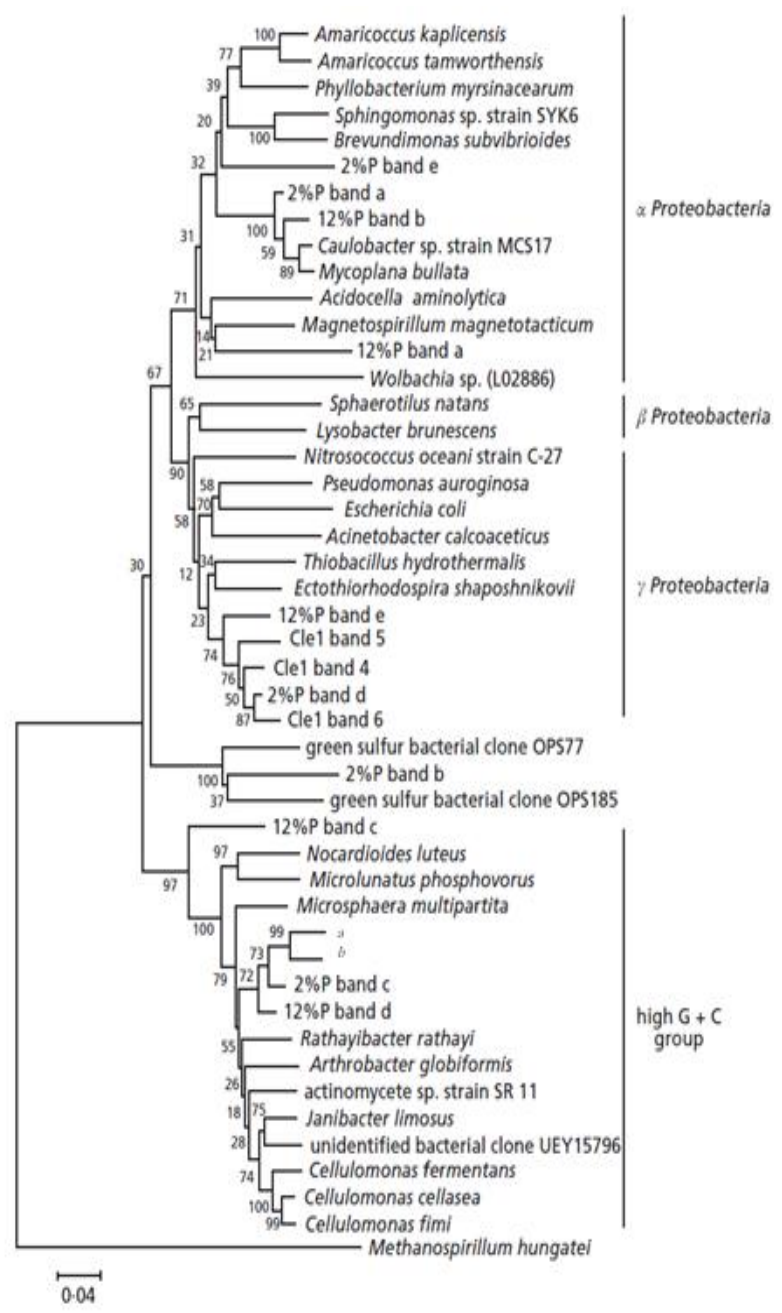

Figure 3. phylogenetic distribution of numerically dominant populations in sludge samples containing either $2 \%$ or $12.3 \%$, based on the partial sequence of $16 \mathrm{~S}$ rDNA genes resolved using DGGE.

\section{REFERENCES}

[1] Bond, P, Erhart, E, Wagner, M, Keller, J. and Blackall, L. (1999). Identification of some of the major groups of bacteria in efficient and non-efficient biological phosphorus removal activated sludge systems. Appl Environ Microbiol 65, 4077-4084.

[2] Bond, P, Hugenholtz, P, Keller, J. and Blackall, L. (1995). Bacterial community structures of phosphate-removing and non-phosphate removing activated sludge from sequencing batch reactors. Appl Environ Microbiol 61, 1910-1916.

[3] Cech, J. S. and Hartman, P. (1993). Competition between polyphosphate and polysaccharide accumulating bacteria in enhanced biological phosphate removal system. Water Res 27, 12191225 .

[4] Collins, M. D. and Jones, D. (1981). Distribution of isoprenoid quinone structural types in bacteria and their taxonomic implications. Microbiol Rev 45, 316-354.

[5] Dawes, E. A. and Senior, P. J. (1973). Energy reserve polymers in microorganisms. Adv Microbiol Physiol 10, 135-266.

[6] Felsenstein, J. (1985). Confidence limits of phylogenies: an approach using the bootstrap. Evolution 39, 783-791.

[7] Felske, A, Wolterink, A, Van Lis, R. and Akkermans, A. D. (1998). Phylogeny of the main bacterial 16S rRNA sequences in Drentse A grassland soils (The Netherlands). Appl Environ Microbiol 64, 871-879.

[8] Ferris, M. J, Muyzer, G. and Ward, D. M. (1996). Denaturing gradient gel electrophoresis profiles of $16 \mathrm{~S}$ rRNA defined populations inhabiting a hot spring microbial mat community. Appl Environ Microbiol 62, 340-346. 
[9] Haack, S. K, Garchow, H, Odelson, D, Forney, L. J. and Klug, M. J. (1994). Accuracy, reproducibility, and interpretation of fatty acid methyl ester profiles of model bacterial communities. Appl Environ Microbiol 60, 2483-2493.

[10] Heuer, H, Krsek, M, Baker, P, Smalla, K. and Wellington, E. M. (1997). Analysis of actinomycete communities by specific amplification of genes encoding 16S rRNA and gelelectrophoretic separation in denaturing gradients. Appl Environ Microbiol 63, 3233-3241.

[11] Hiraishi, A, Masamune, K. and Kitamura, H. (1989). Characterization of the bacterial population structure in an anaerobic aerobic activated sludge system on the basis of respiratory

[12] Hiraishi, A, Ueda, Y. and Ishihara, J. (1998). Quinone pro®ling of bacterial communities in natural and synthetic sewage activated sludge for enhanced phosphate removal. Appl Environ Microbiol 64, 992-998.

[13] Kampfer, P, Erhart, R, Beimfohr, C, Bo\$ hringer, J, Wagner, M. and Amann, R. (1996). Characterization of bacterial communities from activated sludge: culture dependent numerical identi®cation versus in situ identißcation using group- and genus-specißc rRNAtargeted oligonucleotide probes. Microb Ecol 322, 101-121.

[14] Kuba, T, Smolders, G, van Loosdrecht, M. C. M. and Heijnen, J. J. (1993). Biological phosphorus removal from wastewater by anaerobic-anoxic sequencing batch reactor. Water Sci Technol 27, 241-252.

[15] Kumar, S, Tamura, K. and Nei, M. (1993). mega: molecular evolutionary genetics analysis, version 1.0. University Park, PA: Pennsylvania State University.

[16] Lee, N, Nielsen, P. H, Andreasen, K. H, Juretschko, S, Nielsen, J. L, Schleifer, K.-H. and Wagner, M. (1999). Combination of ${ }^{-}$uorescent in situ hybridization and microsutoradiography new tool for structure-function analyses in microbial ecology. Appl Environ Microbiol 65, 12891297.

[17] Liu, W.-T. (1995). Function, dynamics, and diversity of microbial population in anaerobic aerobic activated sludge processes for biological phosphate removal. $\mathrm{PhD}$ thesis, University of Tokyo.

[18] Liu, W.-T, Marsh, T. L, Chen, H. and Forney, L. J. (1997b). Characterization of microbial diversity by determining terminal restriction fragment length polymorphisms of gene encoding 16S rRNA. Appl Environ Microbiol 63, 4516-4522.

[19] Liu, W.-T, Mino, T, Matsuo, T. and Nakamura, K. (1996). Glycogen accumulating population and its anaerobic substrate uptake in anaerobic-aerobic activated sludge without biological phosphate removal. Water Res 30, 75-82.

[20] Liu, W.-T, Mino, T, Nakamura, K. and Matsuo, T. (1994). Role of glycogen in acetate uptake and polyhydroxyalkanoate synthesis in anaerobic-aerobic activated sludge with a minimized polyphosphate content. J Ferment Biotechnol 77, 535-540.

[21] Liu, W.-T, Nakamura, K, Matsuo, T. and Mino, T. (1997a). Internal energy-based competition between polyphosphate- and glycogen accumulating bacteria in biological phosphorus removal reactor -effect of the P\}C feeding ratio. Water Res 31, 1430-1438.

[22] MacRae, J. D. and Smit, J. (1991). Characterization of caulobacters isolated from wastewater treatment systems. Appl Environ Microbiol 573, 751-758.

[23] Mobarry, B. K, Wagner, M, Urbain, V, Rittmann, B. E. and Stahl, D. A. (1996). Phylogenetic probes for analyzing abundance and spatial organization of nitrifying bacteria. Appl Environ Microbiol 62, 2156-2162.

[24] Muyzer, G, de Waal, E. C. and Uitterlinden, A. G. (1993). Pro®ling of complex microbial populations by denaturing gradient gel electrophoresis analysis of polymerase chain reactionampli®ed genes coding for 16S rRNA. Appl Environ Microbiol 59, 695-700.

[25] Muyzer, G, Teske, A. and Wirsen, C. O. (1995). Phylogenetic relationships of Thiomicrospira species and their identi®cation in deep-sea hydrothermal vent samples by denaturing gradient gel electrophoresis of 16S rDNA fragments. Arch Microbiol 164, 165-172.

[26] Nakamura, K, Hiraishi, A, Yoshimi, Y, Kawaharasaki, M, Masuda, K. and Kamagata, Y. (1995). Microlunatus phosphovorus gen. nov, sp. nov, a new gram-positive polyphosphate-accumulating bacterium isolated from activated sludge. Int J Syst Bacteriol 45, 17-22. 
[27] Nielsen, A. T, Liu, W.-T, Philips, C, Grady, L, Jr, Molin, S.and Stahl, D. A. (1999). Identi®cation of a novel group of bacteria in sludge from a deteriorated biological phosphorus removal process. Appl Environ Microbiol 65, 1251-1258.

[28] Picard, C, Ponsonnet, C, Paget, E, Nesme, X. and Simonet, P. (1992). Detection and enumeration of bacteria in soil by direct DNA extraction and polymerase chain reaction. Appl Environ Microbiol 58, 2717-2722.

[29] Rajendran, N, Matsuda, O, Imamura, N. and Urushigawa, Y. (1992). Variation in microbial biomass and community structure in sediments of eutrophic bays as determined by phospholipid ester-linked fatty acids. Appl Environ Microbiol 58, 562-571.

[30] Raskin, L, Stromley, J. M, Rittmann, B. E. and Stahl, D. A. (1994). Group-speci®c 16S rRNA hybridization probes to describe natural communities of methanogens. Appl Environ Microbiol 60, 1232-1240.

[31] Riesner, D, Steger, G, Zimmat, R, Owens, R. A, Wagenhofer, M, Hillen, W, Vollbach, S. and Henco, K. (1989). Temperaturegradient gel electrophoresis of nucleic acids : analysis of conformational transitions, sequence variations, and protein-nucleic acid interactions. Electrophoresis 10, 377-389.

[32] Saitou, N. and Nei, M. (1987). The neighbor-joining method: a new method for reconstructing phylogenetic trees. Mol Biol Evol 4, 406-425.

[33] Schuppler, M, Mertens, F, Scho\$ n, G. and Go\$ bel, U. B. (1995). Molecular characterization of nocardioform actinomycetes in activated sludge by 16 S rRNA analysis. Microbiology 141, 513521.

[34] Schuppler, M, Wagner, M, Scho\$ n, G. and Go\$ bel, U. B. (1998). In situ identi®cation of nocardioform actinomycetes in activated sludge using ${ }^{-}$uorescent rRNA-targeted oligonucleotide probes. Microbiology 144, 249-259.

[35] Shintani, T, Liu, W.-T, Hanada, S, Kamagata, Y, Miyaoka, S, Suzuki, T. and Nakamura, K. (2000). Micropruina glycogenica gen. nov, sp. nov, a new Gram-positive glycogen-accumulating bacterium isolated from activated sludge. Int J Syst Evol Microbiol 50, 201-207.

[36] Stahl, D. A, Key, R, Flesher, B. and Smit, J. (1992). The phylogeny of marine and freshwater caulobacters re ${ }^{-}$ects their habitat. J Bacteriol 174, 2193-2198.

[37] Tebbe, C. C. and Vahjen, W. (1993). Interference of humic acids and DNA extracted directly from soil in detection and transformation of recombinant DNA from bacteria and a yeast. Appl Environ Microbiol 59, 2657-2665.

[38] Thompson, J. D, Higgins, D. G. and Gibson, T. J. (1994). clustal w: improving the sensitivity of progressive multiple sequence alignment through sequence weighting, position-speci®c gap penalties and weight matrix choice. Nucleic Acids Res 22, 4673-4680.

[39] Wagner, M, Erhart, R, Manz, W, Amann, R, Lemmer, H, Wedi, D. and Schleifer, K. H. (1994). Development of an rRNA-targeted oligonucleotide probe speci®c for the genus Acinetobacter and its application for in situ monitoring in activated sludge. Appl Environ Microbiol 60, 792800 .

[40] Wilson, I. G. (1997). Inhibition and facilitation of nucleic acid ampli®cation. Appl Environ Microbiol 63, 3741-3751. 